\title{
Workplace Charging Frequency of Nissan Leafs and Chevrolet Volts in The EV Project at Six Work Sites
}

Don Scoffield, Shawn Salisbury, John Smart

November 2014

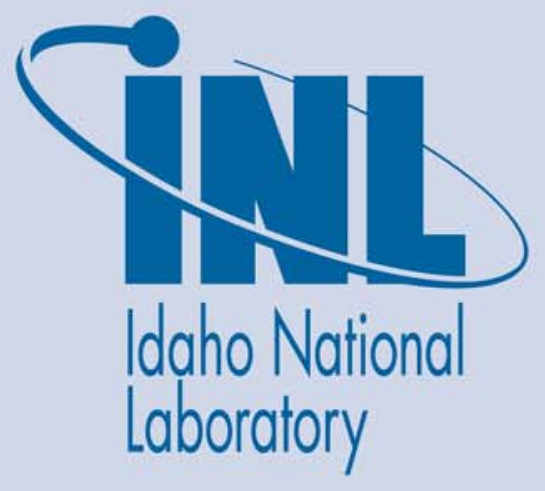

The INL is a U.S. Department of Energy National Laboratory operated by Battelle Energy Alliance 


\section{DRIVING AND CHARGING BEHAVIOR OF NISSAN LEAFS IN THE EV PROJECT WITH ACCESS TO WORKPLACE CHARGING}

Don Scoffield, Shawn Salisbury and John Smart

November 2014

Idaho National Laboratory

Idaho Falls, Idaho 83415

http://www.inl.gov

Prepared for the

U.S. Department of Energy

Office of Energy Efficiency and Renewable Energy

Under DOE Idaho Operations Office

Contract DE-AC07-05ID14517 


\section{VIProject}

\section{Workplace Charging Frequency of Nissan Leafs and Chevrolet Volts in The EV Project at Six Work Sites}

November 2014

\section{Key Conclusions}

- Use of plug-in electric vehicle (PEV) charging infrastructure at six work sites in California varied from site to site, based on a number of factors that include the following:

- The cost of charging

- Employee commute distance

- Demand for charging station use

- Policies for how long a vehicle can be connected to workplace charging stations.

- In general, drivers with longer commutes tended to charge more often at work. However, some employees with short commutes still charged at work when cost was low.

- The work sites studied employed a mix of policies to manage charging station use, including levying fees for charging, requiring the use of a reservation system, providing employees tools to self-manage charging, and requiring drivers to move their vehicles upon completion of charging. At three work sites, the combination of policies employed effectively enabled numerous vehicles to frequently use a fixed number of charging stations. At the other three work sites, the combination of policies chosen resulted in infrequent vehicle charging at work.

\section{Introduction}

With an increase in the number of PEVs on the road, many employers are offering opportunities to charge PEVs at work. The work site seems to be an ideal place for PEV charging because employees are typically parked there between 4 and 10 hours per day. (See Appendix A for more information on the time vehicles are parked at work.) Charging while parked at work can provide energy for extended commuting and provide range confidence. This paper examines work site charging behavior of The EV Project participants who parked and charged at six different work sites in California. Background information on these work sites was obtained directly from the company or from the report, "Amping up California Workplaces: 20 Case Studies on Plug-in Electric Vehicle Charging at Work," published in November 2013 [1]. The frequency of workplace charging was examined, as well as key factors that may have contributed to workplace charging.

\section{Which Vehicles and Work Sites Were Studied?}

For this study, data were analyzed from 47 Nissan Leafs and five Chevrolet Volts participating in The EV Project that frequently charged and/or parked at six different workplaces in California. Four of these work sites were in the San Francisco Bay area and two were in southern California. The number of employees at each company varied from around 100 to over 5,000. The study period for this paper was approximately 2 years, ending December 31,2013 . The starting date at each location varied, based on when charging stations were installed.

The owners of the vehicles reporting data used in this study agreed to allow data to be collected from their vehicles as a term of their participation in The EV Project. Data sets were filtered to only include vehicles whose drivers had a high probability of being employees, rather than visitors, at the work sites in this study. The number of PEVs enrolled in The EV Project at each of these work sites ranged from four to 17 . Table 1 summarizes the number of vehicles from which data were collected that parked at each work site.

Table 1. Number of EV Project vehicles that frequently parked at each work site.

\begin{tabular}{|l|c|c|}
\hline \multicolumn{1}{|c|}{ Work site } & $\begin{array}{c}\text { Number of } \\
\text { PEVs Reporting } \\
\text { Data }\end{array}$ & $\begin{array}{c}\text { Vehicle } \\
\text { Work Days }\end{array}$ \\
\hline Company A & 5 Leafs & 566 \\
\hline Company B & 17 Leafs & 2,350 \\
\hline Company C & 5 Leafs & 650 \\
\hline Company D & 4 Leafs & 685 \\
\hline Company E & 3 Leafs, 5 Volts & 1,379 \\
\hline Company F & 11 Leafs & 3,009 \\
\hline
\end{tabular}

\section{Work Site Descriptions}

Company A's facility consisted of one building and an employee parking garage. Ten alternating current (AC) Level 2 charging stations and one direct current (DC) fast charger were located in the parking garage. These charging stations were available for use by employees and the public through the end of the study period. Over 45 
employees at Company A owned PEVs by the end of the study period.

Company B's campus included numerous buildings in an office park spanning multiple city blocks. The campus contained 31 AC Level 2 and 12 AC Level 1 charging stations that were located in its buildings' parking lots and garages that were available only for the company's fleet and employees. Company B reported that over 100 employees were driving PEVs by fall 2013.

During the study period, Company $\mathrm{C}$ had $12 \mathrm{AC}$ Level 1 charging stations, 22 AC Level 2 charging stations, and one DC fast charger at its main campus. These electric vehicle supply equipment (EVSE) units were installed over time as the number of employees owning PEVs and the demand for workplace charging increased. The charging units were available for use by employees, visitors and the general public. The estimated number of Company $C$ employees driving PEVs by the end of the study period was 50.

Company $D$ had one AC Level 2 charging station that was located in an office building parking lot. This charging unit had two charge ports that reached to four different parking spaces. This charging unit was only allowed to be used by employees.

The Company $\mathrm{E}$ lot is spread out over an entire city block. On the lot, there were four parking structures, with each containing four charging stations. There were also four more charging stations that were distributed across the lot. These chargers were supplied for use by employees, fleet vehicles, and visitors. Company E had 40 to 50 PEVowning employees by fall 2013.

Company $F$ had 43 charging stations that were located across six company locations. These charging stations were provided by the company for its employees and its electric fleet vehicles. At the end of the study period, there were approximately 45 Company $\mathrm{F}$ employees driving PEVs.

Figure 1 summarizes the number of EVSE, number of EV Project vehicles, and the estimated total number of PEVs driven to work by employees at all six work sites. The light blue arrows indicate that charging stations were open for use by non-employees, such as business-related visitors or the general public.

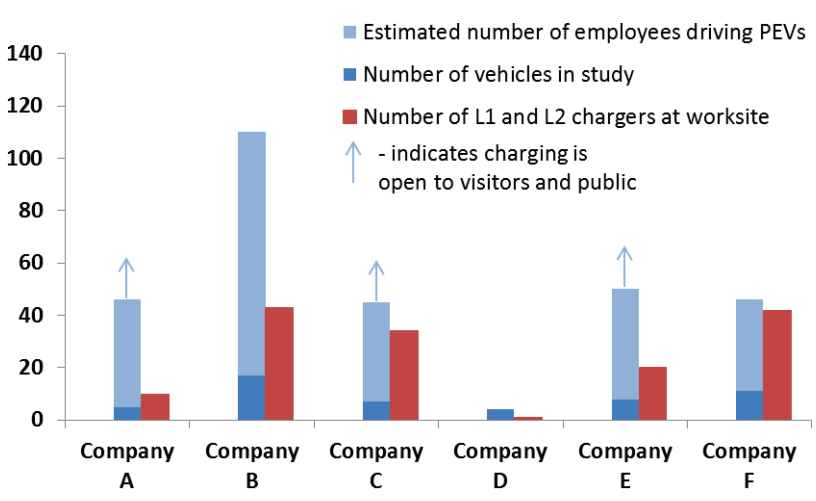

Figure 1. Comparison of the number of PEV drivers and EVSE at each work site.

\section{How Often Did Charging Occur?}

The data were collected over a total of 8,639 vehicle work days at the various work sites. During those work days, there were 10,718 parking events and 2,901 charges performed by the PEV drivers. Figure 2 shows the percentage of days when EV Project vehicles were charged and not charged at each work site. For example, Company A employees enrolled in The EV Project charged their vehicles on over $70 \%$ of their work days. In contrast, the employees at Company $F$ charged their vehicles on only $8 \%$ of their work days.

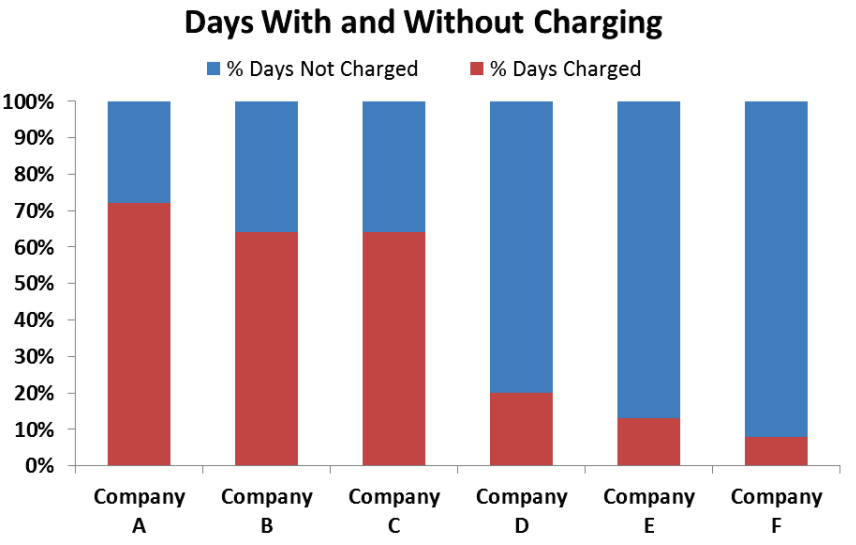

Figure 2. Work site charging frequency.

Figure 2 shows that the usage frequency of workplace charging units at the work sites studied varied from work site to work site. It also varied from vehicle to vehicle at a single work site. Some vehicles were charged everyday when they were parked at the work site, others were charged periodically, and other vehicles were never charged. 


\section{Factors Influencing Charging Behavior}

Several factors contributed to the PEV drivers' use of workplace charging, including the following:

- The cost of charging (free vs. cost)

- Round-trip commuting distance relative to the electric range of the vehicle

- Demand for charging station use, indicated by the ratio of number of PEVs to the number of EVSE at a work site

- The policy for how long a vehicle can be connected to workplace EVSE.

\section{Discussion of Results at Each Work Site}

\section{Company A}

During the study period, charging stations were free to employees. Data available from the AC Level 2 units at this location indicated that these units were highly utilized. The chargers were managed by an online reservation system, which designated a daily time for each participant to use. Company A had a PEV-to-EVSE ratio of 4.6; however, they overcame this limitation through use of the reservation system.

There were five Leafs enrolled in The EV Project, which frequently charged and/or parked at this site. Average charging frequency of these vehicles varied from charging daily to charging once every 4 days. This varied proportionally with the vehicles' average commuting distances.

Data collected from the DC fast charger at Company A showed it was used heavily, averaging 70 charging events per week. However, drivers of the five Leafs contributing data for this study did not use the DC fast charger during the study period. This suggests that Level 2 charging was sufficient for these drivers' workplace charging needs.

\section{Company B}

As of fall 2013, Company B charged a fee for employees to use the charging stations. There was no limit to the time a vehicle can charge, provided employees registered their vehicle with the company and signed a liability waiver.

Out of over 100 PEVs owned by Company B employees, there were $17 \mathrm{EV}$ Project Leafs who regularly parked at this work site. These vehicles were charged on $64 \%$ of the vehicle work days in the study. On first glance, it appears that, like at Company $A$, charging frequency at Company $B$ was proportional to commuting distance. Twelve of the 17 vehicles were charged on at least $50 \%$ of the days. These 12 frequently charged vehicles had an average round-trip commute distance of 48 miles, compared to a 43-mile average commute distance for the five vehicles that were rarely charged. However, examination of individual driver behavior uncovered that four of the vehicles that were charged at work on most work days averaged less than 35 miles round trip between home and work. Why would these drivers be willing to pay to charge often at work when their typical commute was well within their vehicle's range? The cost to charge at Company B was $\$ 0.14$ per kWh plus $\$ 0.41$ per charge. This fee is in the range of some residential electricity rate plans in northern California. Therefore, for some drivers, there may have been little or no cost difference between charging at home and work.

Although the fee charged at Company $B$ did not deter some drivers who live close to work from charging, it appears to have served as an effective tool for managing charging. Even though there were 2.6 vehicles for every EVSE at Company $B$ and there were no rules limiting the time a vehicle spent connected to a charging station, the PEVdriving employees at Company $B$ were able to charge on nearly 2 out of 3 work days.

\section{Company C}

Use of the charging stations at Company $C$ was free for anyone in the study period. Charging station usage at Company $\mathrm{C}$ was coordinated using social media.

There were seven vehicles enrolled in The EV Project that frequently charged and/or parked at Company $C$. Of these seven vehicles, five of them were charged on over $96 \%$ of the days when they parked at work. The other two were never charged at work. There was a strong correlation between commute distance and charging frequency. The five vehicles that were charged nearly every day had an average round-trip commute distance of 56 miles, while the other two vehicles had an average commute distance of 22 miles.

Analysis of data from numerous charging stations at Company $\mathrm{C}$ indicated that the units were nearly constantly in use. Turnover at charging stations was high and many vehicles were charged each day. This was made possible by Company C's decision to allow free charging, its policy encouraging employees to move their vehicles after charging was completed, and providing employees a system for coordinating charging. (For more information on workplace charging at Company $\mathrm{C}$, see [2]).

There was a DC fast charger installed at Company C. However, no vehicles in this study used the DC fast charger during the study period. It seems that Level 1 and Level 2 charging met the workplace charging needs of these drivers.

\section{Company D}

Charging at Company $D$ was free for employees during the study period. PEV drivers were asked to park in the 
assigned charging spaces and to move their vehicle when it completed charging.

Four EV Project Nissan Leafs frequently parked at Company D. Overall, these vehicles were only charged on $20 \%$ of vehicle work days. Further inspection revealed that two vehicles were charged often, while the other two vehicles were rarely charged. There was only a slight correlation between commuting distance and charging frequency. The disparity in charging frequency, despite similar commuting distances and free charging, suggests that there were other local factors motivating behavior.

\section{Company E}

Employees at Company $E$ were required to pay a fee to charge onsite. There was also a policy in place that required drivers to move their vehicles after they had completed charging. This policy was enforced by parking security.

Five Chevrolet Volts and three Nissan Leafs enrolled in The EV Project charged and/or parked at this site. These vehicles were only charged at Company $E$ on $13 \%$ of their work days. Of the eight vehicles in the study, one Volt did most of the charging, with that vehicle's average round-trip commute distance exceeding its electric-only operating range. The rest of the vehicles had short commutes, relative to their vehicles' electric-only operating range; therefore, there was not a strong need for charging at work. The cost to charge at Company $E$ was $\$ 1.00$ per hour connected, which equates to about $\$ 0.33$ per $\mathrm{kWh}$ for the Leafs and Volts in this study.

\section{Company F}

PEV drivers at Company $F$ paid a fee of $\$ 0.17$ to $\$ 0.27$ per $\mathrm{kWh}$, depending on the time of year, to use the charging stations. There were no time limits involved with using the charging stations. However, drivers were encouraged to display a card on the vehicle's dashboard, indicating when the vehicle was expected to be fully charged, so that another driver could use the charging station after that time.

Company $F$ had a PEV-to-EVSE ratio of 1.1 , the lowest of the six work sites in the study. Despite this low ratio, Company $F$ had the fewest number of work days where charging occurred (i.e., 8\%). This may have been due to low commuting distance. The 11 EV Project Nissan Leafs that frequently parked at Company $F$ averaged 24 miles round-trip between home and work. Nearly $90 \%$ of daily round-trip commutes were 40 miles or less.

\section{Summary}

Figure 3 summarizes the discussion above by overlaying information about each work site on the charging frequency chart shown in Figure 2. The range of average round-trip commuting distances for the vehicles at each work site is shown in the figure, with the overall average round-trip commuting distance of all vehicles at a work site represented by a blue diamond.

In general, charging frequency was proportional to commuting distance. This correlation was stronger at the two work sites that charged fees that substantially exceeded the cost of charging at home.

Company A, Company C, and Company B employed different policies and tools, which effectively allowed a large number of PEV drivers to charge frequently at work. Charging frequency was low at Company $D$, even though the equipment installed and policy for use should have been enough to support frequent charging. This highlights the need to understand local nuances at companies with a small number of PEV drivers and EVSE. The combination of low commuting distance and fees at Company $E$ and Company $F$, as well as the strictly enforced policy for length of time of use at Company $E$, led to low charging frequency at these work sites.

\section{Considerations for Policy Decisions}

Some considerations for managing workplace charging can be taken from this study.

First, imposing a fee to charge at work will likely reduce charging station use. However, if fees are too high and/or employee commuting distances are low, charging equipment may be seldom used.

Second, providing PEV-owning employees tools to selfmanage charging can be an effective way to maximize charging station use and accommodate a lot of vehicles, even if charging is free.

Third, an enforced policy requiring drivers to move their vehicles from parking spaces designated for charging is a deterrent to workplace charging. Employees may be disinclined to risk a reprimand or fine if they are unable to interrupt their work day to unplug and move their vehicles at the required time.

Finally, corporate culture may affect employees' workplace charging behavior. For example, if a company executive owns a PEV, lower-ranking employees may be reluctant to use a charging station that the executive uses. Likewise, employees with a particular status or background may feel entitled to occupy a charging station for as long as they want, without regard to other employees' desire to charge. Naturally, these cases could occur at any work site, but they may be more likely to occur and will have a more significant effect at smaller work sites. 


\section{EV/Project}

\section{Summary of Factors Influencing Workplace Charging Frequency}

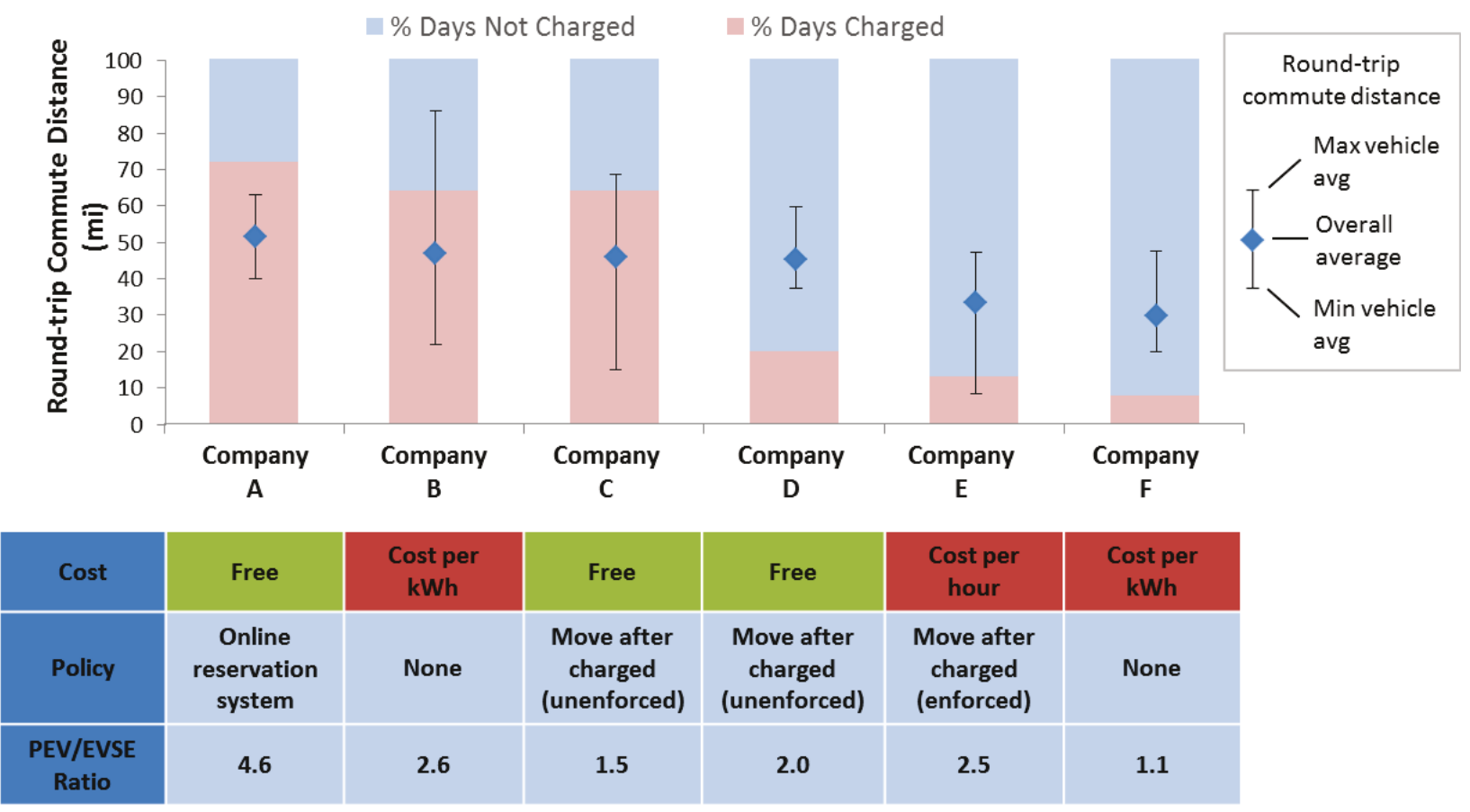

Figure 3. Summary of factors influencing workplace charging frequency and observed charging frequency at the six work sites.

\section{About The EV Project}

The EV Project was the largest PEV infrastructure demonstration project in the world, equally funded by the United States Department of Energy (DOE) through the American Recovery and Reinvestment Act and private sector partners. The EV Project deployed over 12,000 AC Level 2 charging stations for residential and commercial use and over 100 dual-port DC fast chargers in 17 U.S. regions. Approximately 8,300 Nissan LEAFs ${ }^{\mathrm{TM}}$, Chevrolet Volts, and Smart ForTwo Electric Drive vehicles were enrolled in the project.

Project participants gave written consent for EV Project researchers to collect and analyze data from their vehicles and/or charging units. Data collected from the vehicles and charging infrastructure represented almost 125 million miles of driving and 4 million charging events. The data collection phase of The EV Project ran from January 1, 2011, through December 31, 2013. Idaho National Laboratory is responsible for analyzing the data and publishing summary reports, technical papers, and lessons learned on vehicle and charging unit use.

For more information about The EV Project, visit avt.inl.gov/evproject.shtml.

\section{Company Profile}

Idaho National Laboratory is one of DOE's 10 multi-program national laboratories. The laboratory performs work in each of DOE's strategic goal areas: energy, national security, science, and the environment. Idaho National Laboratory is the nation's leading center for nuclear energy research and development. Day-to-day management and operation of the laboratory is the responsibility of Battelle Energy Alliance.

For more information about INL, visit www.inl.gov.

\section{References}

[1] "Amping up California Workplaces: 20 Case Studies on Plug-in Electric Vehicle Charging at Work," California Plugin Electric Vehicle Collaborative, November 2013, www.pevcollaborative.org/sites/all/themes/pev/files/WPC R eport4web.pdf.

[2] "Workplace Charging Case Study: Charging Station Utilization at a Work Site with AC Level 1, AC Level 2, and DC Fast Charging Units," Idaho National Laboratory, June 2014,

avt.inl.gov/pdf/EVProj/WorkplaceEVSEUtilizationAtFacebo okJun2014.pdf. 


\section{Appendix A}

\section{Time Spent Parked at Work}

The distribution of time that each vehicle was parked per day at any of the six work sites in this study is shown in Figure A1. Days were only included in this analysis if vehicles were parked at work for more than 4 hours. The time represents the total time parked during a work day, even if that parking was broken up by driving throughout the day.

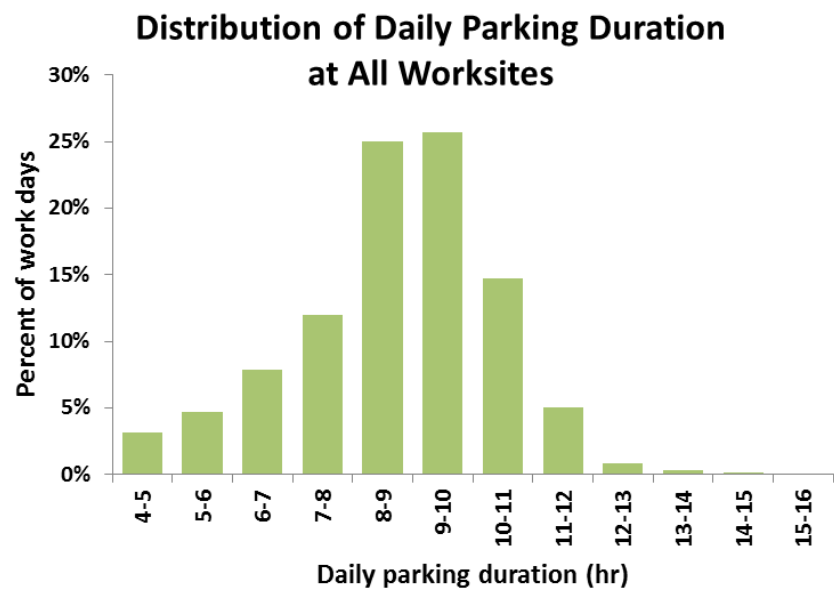

Figure A1. Distribution of time parked per day at work.

This figure shows that vehicles in this study spent between 8 and 10 hours parked at work on over half of their work days.

\section{Calculation of Commute Distance}

For this analysis, the round-trip commute distance was defined in the following manner. A vehicle's round-trip commute distance is the sum of all miles driven from home to work and work to home, including any driving in between (such as going to lunch). For example, if a driver has to drop off a child at school before going to work in the morning, that total distance (from home to school to work) is included in their daily round-trip commute distance. If at lunch, they leave work and go to a restaurant and then drive back to work, then those distances are also included (from work to restaurant to work). Finally, the distance from work to home is added to complete the round-trip distance for that day. Any more driving miles that occur after arriving at home from work are not included in the round-trip commute distance (such as a trip to the grocery store).

Figure A2 depicts this example, with the distance components included in the round-trip commute calculation as green lines.

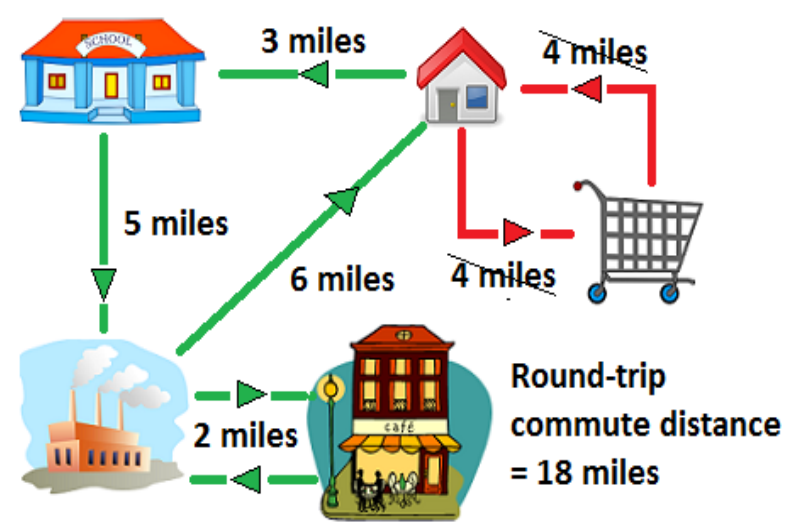

Figure A2. Components of a round-trip commute.

All daily commutes by the vehicles in this study were included in a single distribution, which is shown in Figure A3.

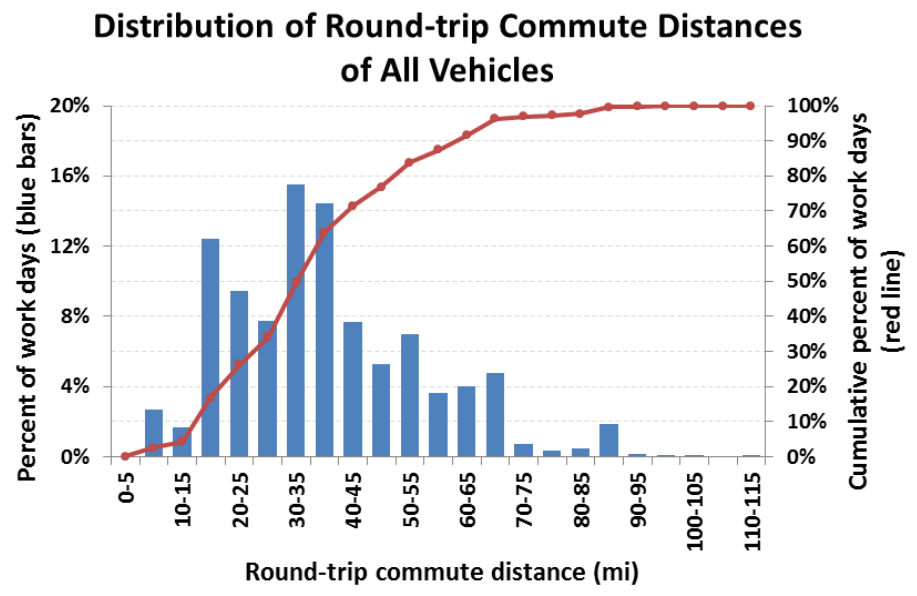

Figure A3. Distribution of round-trip commute distance.

This figure shows that $64 \%$ of round-trip commutes were 40 miles or less. 